11) De Groot, J.: The rat forebrain in stereotaxic coordinates. Verh. K. ned. Alad. Wet. 62, 3-41 (1959)

12) Leaf, R.C., Lerner, L. ANd Horovitz, Z.P.: The role of the amygdala in the pharmacological and endocrinological manipulation of aggression. Aggressive Behavior, Edited by Garattini, S. And SigG, E.B., p. 120-131, Exerpta Medica Foundation, Amsterdam (1969)

\title{
EFFECTS OF INTRACEREBRAL INJECTION WITH MUSCIMOL ON LOCOMOTOR ACTIVITY AND CATALEPSY IN RATS
}

\author{
Yoshiki MATSUI and Toshiharu KAMIOKA \\ Central Research Laboratories, Sankyo Co., Ltd., Hiromachi 1-chome, \\ Shinagawa-ku, Tokyo 140, Japan
}

Accepted February 7, 1979

Recently, studies have been published concerning the relationship between brain GABA function and behaviour, for example, GABA elevation in nigra induced hyperactivity (1), and pallidal GABA elevation induced akinesia (2). In addition to these two areas, the nucleus accumbens (AC), caudate nucleus (CD), and amygdaloid nucleus (AM) also contain a high concentration of GABA and/or glutamate decarboxylase (3-5). Furthermore, these latter mentioned areas are innervated with dopaminergic fiber originating in the mesencephalon (6). Thus, it is conceivable that GABA in these areas plays an important role in regulation of behaviour. In this paper, effects of muscimol, a potent and specific GABA agonist (7), on locomotor activity and catalepsy were studied after injection of the drug into AC, CD, AM and pallidum (GP).

Male Wistar-Imamichi rats (300-350 g) were anesthetized with pentobarbital sodium (Nembutal, $40 \mathrm{mg} / \mathrm{kg}$, i.p.) and guide cannulae (o.d. $0.75 \mathrm{~mm}$ ) were mounted stereotaxically on the skull 4 days before experiments. The stereotaxic atlas of Pellegrino and Cushman (8) was used and coordinates were AC (AP; 3.2, L; 2.0, V; 7.5), CD (AP; 2.0, L; 3.0, V; 4.5), GP (AP; 1.0, L; 2.8, V; 6.5) and AM (AP; 0.2, L; 5.0, V; 8.0) (Ventral coordinates were from the brain surface). Muscimol (100 ng in $0.5 \mu l$ saline) which was synthesized in our laboratories, or saline $(0.5 \mu \mathrm{l})$ was injected bilaterally through the guide cannulae in nonanesthetized rats using a stainless steel needle (o.d. $0.35 \mathrm{~mm}$ ) connected to a Hamilton microsyringe with polyethylene tubing. Locomotor activity was measured with Valimex (Columbus Instruments, Ohio) from 10 to 15 min after muscimol injection and 20 min after injection, the degree of catalepsy was measured. The intensity of catalepsy was considered the time the animals placed both forelimbs on a horizontal bar $10 \mathrm{~cm}$ high and remained immobile. The brains of all animals were examined histologically for confirmation of the site of injection.

Fig. 1 shows the effect of muscimol on locomotor activity. When muscimol was injected into GP, rats showed little locomotor activity. Injection into $\mathrm{CD}$ decreased 


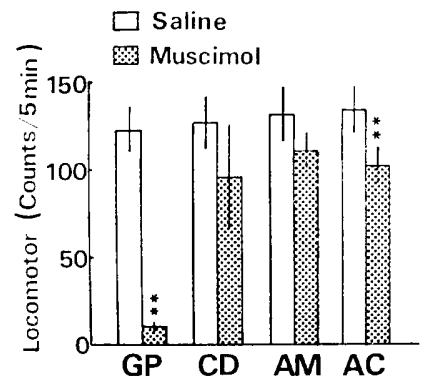

FIG. 1. Effect of intracerebral injection of muscimol or saline on locomotor activity.

Each column shows the mean \pm S.E.M. from 5 animals. $* * p<0.01$

(Student's $t$-test), compared with saline injection group.
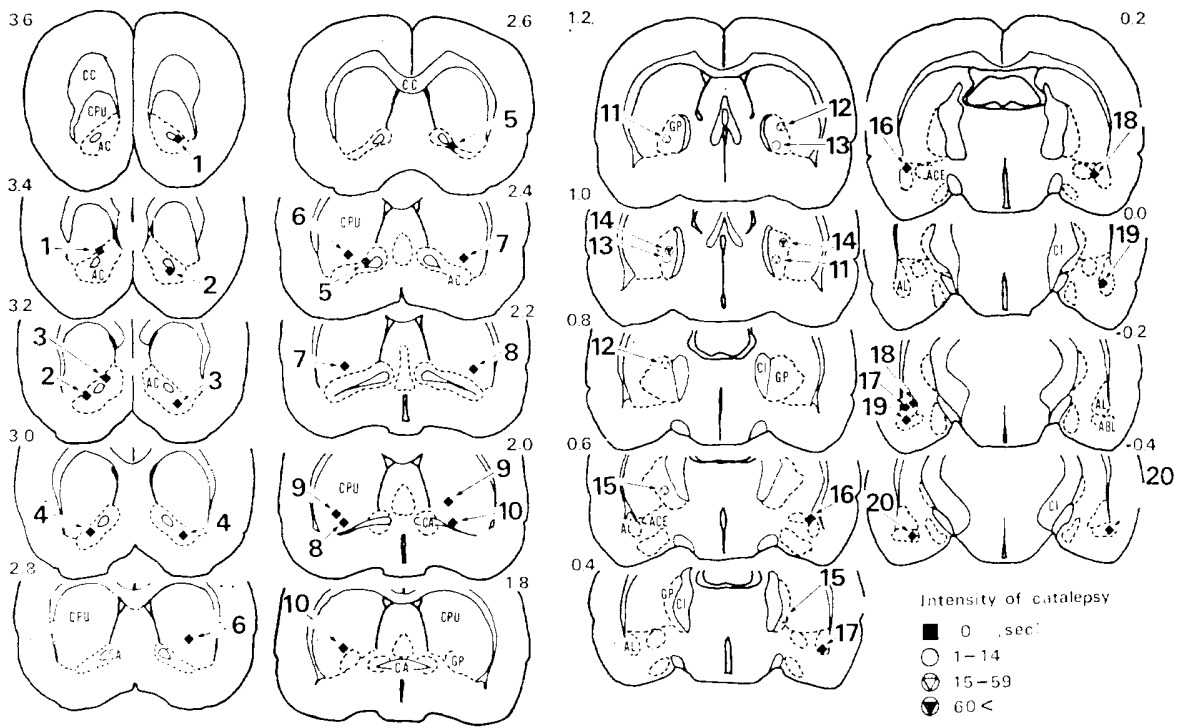

FIG. 2. Injection site of muscimol and intensity of catalepsy. Area of injection; Rats 1-5; AC, 6-10; CD, 11-15; GP, 16-20; AM. Abbreviations: ABL; Basal amygdaloid nucleus, lateral part. AC; Nucleus accumbens septi. ACE; Central amygdaloid nucleus. AL; Lateral amydgaloid nucleus. CA; Anterior commissure. CC; Corpus callosum. Cl; Capsula interna. CPU; Caudate nucleus, Putamen. GP; Globus pallidus.

locomotor activity slightly but not significantly. The decrease shown in Fig. 1 was due to behaviour of just two rats (No. 9 and 10), in which muscimol was injected into CD just anterior to GP. The remaining three rats showed normal locomotor activity. Injection into $\mathrm{AM}$ induced no changes in locomotor activity. Injection into $\mathrm{AC}$ decreased locomotor activity slightly but significantly.

As shown in Fig. 2, pallidal injection with muscimol produced catalepsy. Injection into other areas did not induce catalepsy. Pycock et al. (2) also observed a decrease in locomotor activity induced by pallidal injection of GABA transaminase inhibitor. However, in their experiment, GABA increased not only in GP but also in other areas as well. Thus, 
muscimol injection into $\mathrm{AC}, \mathrm{AM}$ and $\mathrm{CD}$ did not induce a marked decrease in locomotor activity and catalepsy. It is probable that GABA elevation or stimulation of GABA receptor in GP induced a decrease in locomotor activity and catalepsy. Furthermore, in view of the fact that GP is the principle outflow of the basal ganglia (9) GABA function in GP seems to play an important role in inhibition of motor function. Many studies indicate that intraventricular or intraperitoneal injection with GABA mimetic agents produce sedation, akinesia and catalepsy (10-12). From the present results, these behavioural changes are probably induced by the effect of the drugs on the pallidal GABA system.

Injection into $\mathrm{AC}$ also decreased locomotor activity. It is unlikely that the decrease is due to the diffusion of muscimol into the caudal area, i.e. GP, because three rats in which muscimol was injected into $\mathrm{CD}$ (which is nearer to GP than AC), showed normal locomotor activity $15 \mathrm{~min}$ after the injection. Therefore, GABA function in the AC may also have an inhibitory effect on locomotor activity.

Injection into $\mathrm{AM}$ or $\mathrm{CD}$ induced no change in locomotor activity and catalepsy. It is well known that AM is closely related to emotional behaviour (13), therefore, behavioural effects of GABA in AM should be studied. Cools and Janssen (14) reported that GABA injection into specific regions in cat caput nuclei induced ipsilateral turning. Therefore, the possibility remains that GABA in $\mathrm{CD}$ is involved in regulation of motor function. Muscimol should also be injected into specific regions in $C D$ when attempting to study the function of GABA in the CD.

\section{REFERENCES}

1) Matsui, Y. and Kamioka, T.: The effect of elevating $\gamma$-aminobutyrate content in the substantia nigra on the behaviour of rats. Europ. J. Pharmacol. 50, 243-251 (1978)

2) Pycock, C.J., Horton, R.W. And Marsden, C.D.: The behavioural effects of manipulating GABA function in the globus pallidus. Brain Res. 116, 353-359 (1976)

3) EnNa, S.J., Kuhar, M.J. AND SNyder, S.H.: Regional distribution of postsynaptic receptor binding for gamma-aminobutyric acid (GABA) in monkey brain. Brain Res. 93, 168-174 (1975)

4) Balcom, G.J., Lenox, R.H. ANd Meyerhoff, J.L.: Regional $\gamma$-aminobutyric acid levels in rat brain determined after microwave fixation. J. Neurochem. 24, 609-613 (1975)

5) Ben-Ari, Y., Kanazawa, I. and Zigmond, R.E.: Regional distribution of glutamate decarboxylase and GABA within the amygdaloid complex and stria terminalis system of the rat. J. Neurochem. 26, 1279-1283 (1976)

6) UNGERSTEDT, U.: Stereotaxic mapping of the monoamine pathway in the rat brain. Acta physiol. scand. Suppl. 367, 1-48 (1971)

7) Naik, S.R., GuidotTI, A. And Costa, E.: Central GABA receptor agonists: Comparison of muscimol and baclofen. Neuropharmacology 15, 479-484 (1976)

8) Pellegrino, L.J. and Cushman, A.J.: Stereotaxic Atlas of the Rat Brain, Edited by Eliott, R.M., Lindzey, G. and MacCorquodale, K., Appleton-Century-Crofts, New York (1967)

9) Johnson, T.N. AND Rosvold, H.E.: Topographic projection on the globus pallidus and substantia nigra of selectively placed lesions in the precommissural caudate nucleus and putamen in the monkey. Expl Neurol. 33, 584-596 (1971)

10) Matsui, Y. and Deguchi, T.: Effects of gabaculine, a new potent inhibitor of gammaaminobutyrate transaminase, on the brain gamma-aminobutyrate content and convulsions in mice. Life Sci. 20, 1291-1296 (1977)

11) Biggio, G., Casu, M., Corda, M.G., Vernaleone, F. and Gessa, G.L.: Effect of muscimol, 
a GABA-mimetic agent, on dopamine metabolism in the mouse brain. Life Sci. 21, 525-532 (1977)

12) Benton, D. AND Rick, J.T.: The effect of increased brain GABA produced by aminooxyacetic acid on arousal in rats. Psychopharmacology 49, 85-89 (1976)

13) Delgado, J.M.R.: Free behaviour and brain stimulation. International Review of Neurobiology, Edited by Pfeiffer, C.C. And Smythies, J.R., Vol. 6, p. 349-449, Academic Press, New York and London (1964)

14) CoOls, A.R. AND JANSSEN, H.-J.: $\gamma$-Aminobutyric acid: the essential mediator of behaviour triggered by neostriatally applied apomorphine and haloperidol. J. Pharm. Pharmacol. 28, 70-74 (1976)

\title{
ACCUMULATION OF ${ }^{3} \mathrm{H}$-DIGITOXIN IN CNS OF CATS WITH A HYPERSENSITIVITY TO THE DRUG
}

\author{
Sumiko FUJINO, Hideki TSUKADA*, Mamoru TANAKA*, \\ Takashi IGARASHI and Katsuji HOSHI \\ Department of Pharmacology of Hokkaido Pharmaceuticul Sciences, Katsuraoka, \\ Otaru 047-02 and *Department of Pharmacology, Sapporo Medical College, Minami I-Jo, \\ Nishi 17-chome, Chuo-ku, Sapporo 060, Japan
}

Accepted February 14, 1979

Considerable literature (1-6) is available on "the cumulative effect of digitalis", but the mechanism involved in the appearance of this "cumulative effect" is still a matter of speculation. Previous reports suggest the possibility that cardiac glycosides may produce their effects on the heart through the central nervous system (CNS) $(7,8)$. The present work was designed to determine whether "the cumulative effect of digitalis" occurs as a result of the central accumulation of digitalis or is due to the cardiac accumulation of the drug.

The experiment was carried out using cats. At both one and 48 hours after a single injection $\left(17 \mu \mathrm{ci} / 132 \mu \mathrm{g} / \mathrm{kg}\right.$ ) of ${ }^{3} \mathrm{H}$-digitoxin (New England Nuclear Corp., S.A. : $26 \mathrm{mci} / \mathrm{mg}$ ), the following procedures were carried out; 1) determination of both arrhythmic and lethal doses of digitoxin by Hatcher's method, 2) measurement of glycoside (digitoxin and its metabolites) content in the medulla, midbrain, heart, kidney and liver by means of the combustion method (Tri-Carb sample oxidizer, Packard Model 305). Radioactivity was determined using a liquid scintillation spectrometer. $\mathrm{CHCl}_{3}$ soluble extracts were separated by a thin layer chromatographic technique after a $\mathrm{CHCl}_{3}$-extraction from the homogenate of the each tissue.

At 48 hours after the injection, both arrhythmic dose $(190 \pm 25 \mu \mathrm{g} / \mathrm{kg})$ and lethal dose $(317 \pm 33 \mu \mathrm{g} / \mathrm{kg})$ of digitoxin were decreased to one half of each control value (arrhythmic dose; $423 \pm 45 \mu \mathrm{g} / \mathrm{kg}$, lethal dose; $660 \pm 43 \mu \mathrm{g} / \mathrm{kg}$ ). At one hour after the injection, both arrhythmic and lethal doses were found to be much the same as the control values. Fortyeight hours after the injection of digitoxin, a marked hypersensitivity to the drug was seen 